\title{
Possible involvement of G-proteins and cAMP in the induction of progesterone hydroxylating enzyme system in the vascular wilt fungus Fusarium oxysporum
}

\author{
Anna Poli ${ }^{\mathrm{a}, *}$, Antonio Di Pietro ${ }^{\mathrm{b}}$, Dusan Zigon ${ }^{\mathrm{c}}$, Helena Lenasi ${ }^{\mathrm{a}}$ \\ a Institute of Biochemistry, Faculty of Medicine, University of Ljubljana, Vrazov Trg 2, 1000 Ljubljana, Slovenia \\ ${ }^{\mathrm{b}}$ Departamento de Genetica, Universidad de Cordoba, Campus de Rabanales Edificio C5, 14071 Cordoba, Spain

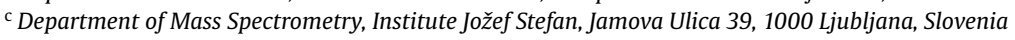

\section{A R T I C L E I N F O}

\section{Article history:}

Received 27 August 2008

Received in revised form 6 November 2008

Accepted 13 January 2009

\section{Keywords:}

Fusarium oxysporum

Progesterone

Steroid hydroxylation

Detoxification

Mitogen-activated protein kinase (MAPK)

G-protein $\beta$ subunit

cAMP

\begin{abstract}
A B S T R A C T
Fungi present the ability to hydroxylate steroids. In some filamentous fungi, progesterone induces an enzyme system which converts the compound into a less toxic hydroxylated product. We investigated the progesterone response in the vascular wilt pathogen Fusarium oxysporum, using mass spectrometry and high performance liquid chromatography (HPLC). Progesterone was mainly transformed into $15 \alpha$-hydroxyprogesterone, which was found predominantly in the extracellular medium. The role of two conserved fungal signaling cascades in the induction of the progesterone-transforming enzyme system was studied, using knockout mutants lacking the mitogen-activated protein kinase Fmk1 or the heterotrimeric G-protein $\beta$ subunit Fgb1 functioning upstream of the cyclic adenosine monophosphate (cAMP) pathway. No steroid hydroxylation was induced in the $\Delta f g b 1$ strain, suggesting a role for the $\mathrm{G}$-protein $\beta$ subunit in progesterone signaling. Exogenous cAMP restored the induction of progesteronetransforming activity in the $\Delta f g b 1$ strain, suggesting that steroid signaling in F. oxysporum is mediated by the cAMP-PKA pathway.
\end{abstract}

(c) 2009 Elsevier Ltd. All rights reserved.

\section{Introduction}

The ability to hydroxylate steroids has been demonstrated in ascomycetes, basidiomycetes and zygomycetes [1]. This biotransformation is economically relevant, because certain steroid metabolites are pharmacologically active and can be used in the synthesis of other steroids [2]. Specifically, the filamentous fungi Rhizopus nigricans and Cochliobolus lunatus were shown to convert the steroid progesterone into the pharmaceutically important compound $11 \alpha$-hydroxyprogesterone [3,4]. Although the biological role of progesterone transformation in fungi is currently unknown, it has been suggested as a mechanism for enzymatic detoxification of a fungitoxic substrate [5]. This hypothesis is supported by several lines of evidence. First, progesterone inhibits hyphal growth of $R$. nigricans and severely affects its morphology [6]. Second, the hydroxylated product is more water-soluble and therefore easily removed from mycelia surrounded by water [5]. Third, progesterone hydroxylase in $R$. nigricans is an inducible cytochrome P450-containing enzyme system which is involved in the transformation of xenobiotics [7].

The mechanisms of progesterone sensing in fungi and the signaling cascades leading to induction of the enzyme system have been

\footnotetext{
* Corresponding author. Tel.: +3861543 7640; fax: +38615437641.

E-mail address: anna.poli@gmail.com (A. Poli).
}

investigated in $R$. nigricans. Specific G-protein-coupled progesterone receptors have been detected in plasma membrane fractions [8] as well as in the cytosol [9]. Heterotrimeric G-protein $\beta$ subunits and cyclic adenosine monophosphate (cAMP) have also been shown to play a key role in the mechanism of enzyme induction by progesterone [6].

The ability to hydroxylate steroidal substrates such as progesterone has also been reported in plant pathogenic species, including those of the genus Fusarium such as F. moniliforme [10], F. solani [11], F. culmorum and F. lini [12]. In Fusarium, introduction of the hydroxyl group occurs most frequently at the $15 \alpha$ position of progesterone and other steroidal skeletons such as testosterone, androstenedione or estrone [12-15]. The most widespread species of the genus is $F$. oxysporum, a soilborne pathogen which causes vascular wilt disease in a wide variety of crops [16]. Isolates of $F$. oxysporum are classified into more than 100 formae speciales, depending on the plant species they infect [17]. The fungus enters the roots through penetration hyphae and colonizes the cortex by intercellular and intracellular growth. After reaching the vascular tissue, it rapidly spreads upwards through the xylem vessels, provoking the typical wilt symptoms. Two conserved signaling components, the mitogen-activated protein kinase (MAPK) Fmk1 and the heterotrimeric G-protein $\beta$ subunit which functions upstream of a cAMP pathway were shown to be required for virulence of $F$. oxysporum f.sp. lycopersici on tomato plants $[18,19]$. F. oxysporum f.sp. cubense responsible for Panama disease on banana, was shown 
previously to hydroxylate progesterone by introducing a hydroxyl group at position $15 \alpha$ [14]. We found that progesterone hydroxylase in F. oxysporum is induced by the presence of the steroidal substrate, as in other fungi $[3,4]$, and proceeded to investigate the underlying mechanism of signal transduction by the mean of target knockout strains. The present work aims to give insight into the possible pathways leading to cytochrome P450-mediated steroid detoxification observed in several filamentous fungal species.

\section{Materials and methods}

\subsection{Chemicals}

Progesterone, cycloheximide, phleomycin, hygromycin, potato dextrose, glutathione and 3'-5'-cyclic adenosine monophosphate (cAMP) were from Sigma-Aldrich (Maribor, Slovenia). All other chemicals used were from Carl Roth (Germany) or Merck (Darmstadt, Germany). 15 $\alpha$-hydroxyprogesterone was kindly supplied by Prof. Zigon. Cellulose nitrate filters (pore diameter $1.2 \mu \mathrm{m}$ ) were from Sartorius Biolab (Goettingen, Germany).

\subsection{Microorganisms and media}

F. oxysporum f.sp. lycopersici wild type strain 4287 (race 2) and knockout mutants $\Delta f m k 1, \Delta f g b 1$ and $\Delta f m k 1 / \Delta f g b 1$ derived thereof $[18,19]$ were stored as microconidial suspensions at $-80^{\circ} \mathrm{C}$ with $30 \%$ glycerol [20]. To prepare inocula, cultures were grown on potato dextrose broth (PDB) in a rotary shaker at $28^{\circ} \mathrm{C}(180$ revolutions per minute (rpm)) for 4 days. Fresh microconidia were obtained by filtration through Miracloth, and the concentration was adjusted to $10^{8} \mathrm{ml}^{-1}$. In some experiments, $10 \mathrm{mM}$ cAMP was added to the culture medium.

\subsection{Progesterone hydroxylating enzyme induction assay}

To test the ability of progesterone to induce progesterone hydroxylase, condia of the wild type and mutant strains were germinated and grown at $28^{\circ} \mathrm{C}$ and $180 \mathrm{rpm}$ for $16 \mathrm{~h}$, before $150 \mu \mathrm{M}$ progesterone or $0.1 \%$ dimethylformamide (DMF) as a control, was added to the medium and cultures were incubated for an additional $2 \mathrm{~h}$ at $28^{\circ} \mathrm{C}$ [7]. Following filtration through a cellulose nitrate filter $(1.2 \mu \mathrm{m})$ and abundant washing, $1 \mathrm{~g}$ (fresh weight) of mycelium was incubated with $15 \mathrm{ml}$ induction buffer $\left(0.8 \mathrm{mM} \mathrm{Na}_{3} \mathrm{PO}_{4}, 0.2 \mathrm{mM}\right.$ EDTA and $0.04 \mathrm{mM}$ gluthathione; pH 5.5), $355 \mu \mathrm{M}$ cycloheximide (a protein synthesis inhibitor to avoid production of new enzyme) and $150 \mu \mathrm{M}$ progesterone as a substrate. The enzymatic reaction was terminated after $30 \mathrm{~min}$ by chloroform addition and extraction. For time course experiments of progesterone transformation and extrusion of hydroxylated products into the medium, cultures were incubated for different times after addition of $30 \mu \mathrm{M}$ progesterone (0-240 min), and chloroform extraction was directly performed on filtered mycelium and on the medium.

\subsection{HPLC analysis and liquid chromatography-mass spectrometry (LC-MS)}

Progesterone and its derivatives in chloroform extracts were analyzed by HPLC, using a ODS Hypersil C-18 column $(5 \mu \mathrm{m}$, $250 \mathrm{~mm} \times 4 \mathrm{~mm}$; Thermo Scientific, Waltham, USA) and a mixture of $40 \%$ water: $60 \%$ acetonitrile as mobile phase.

Mass measurements were run on a hybrid quadruple time of flight mass spectrometer (Q-TOF) provided with an orthogonal Z-spray ESI interface (Waters Micromass, Manchester, UK). Mass spectrometer was interfaced to an ultra performance liquid chromatography (UPLC) system based on a Waters Acquity (Waters, Milford, USA) binary pump with a BEH C-18 column $(1.7 \mu \mathrm{m}$,
$50 \mathrm{~mm} \times 2.1 \mathrm{~mm}$ i.d.). The mobile phases consisted of water and acetonitrile with mixture of $0.1 \%$ of formic acid in water. Compressed nitrogen (99.999\%, Messer, Slovenia) was used as both the drying and the nebulizing gas. The nebulizer gas flow rate was set to approximately $20 \mathrm{~L} / \mathrm{h}$ and the desolvation gas flow rate to $600 \mathrm{~L} / \mathrm{h}$. A cone voltage of $30 \mathrm{~V}$ and a capillary voltage of $2.7 \mathrm{kV}$ were used in positive ion mode. The desolvation temperature was set to $250^{\circ} \mathrm{C}$ and the source temperature to $150^{\circ} \mathrm{C}$. The mass resolution of approximately 9500 was used for determination of elemental composition with TOF mass spectrometer. Full width of the peak was measured at half of its maximum height. MS and MS/MS spectra were acquired in centroid mode over an $\mathrm{m} / \mathrm{z}$ range of $50-1000$ in scan time $0.25 \mathrm{~s}$ and inter scan time $0.05 \mathrm{~s}$. For MS/MS experiments, argon (99.995\%, Messer Slovenia) was used as collision gas at a pressure of approximately $2 \times 10^{-5}$ mbar in the collision cell. Product ion spectra were generated at collision energies profile: $10-30 \mathrm{~V}$. The detector potential was set to $2300 \mathrm{~V}$. The data station operating software was Mass Lynx v 4.1 (Micromass, Manchester).

\subsection{Toxicity assay}

To determine the effect of progesterone and its derivatives on colony growth, a drop of water containing $10^{5}$ microconidia was placed on the center of potato dextrose agar (PDA) plates containing $30 \mu \mathrm{M}$ progesterone or $0.1 \% \mathrm{DMF}$ as a control. Plates were incubated at $28^{\circ} \mathrm{C}$ and the colony diameter was measured each day. To determine the effect of progesterone on mycelial growth, $2.5 \times 10^{7}$ freshly obtained microconidia were inoculated in $100 \mathrm{ml}$ liquid PDB containing $30 \mu \mathrm{M}$ or $150 \mu \mathrm{M}$ progesterone or $0.1 \%$ DMF as a control. After $18 \mathrm{~h}$ incubation at $28^{\circ} \mathrm{C}$ and $180 \mathrm{rpm}$, the fungal mycelium was harvested by filtration through a $1.2 \mu \mathrm{m}$ filter, dried overnight at $80^{\circ} \mathrm{C}$, and mycelial dry weight was determined.

For morphological analysis, fungal strains were grown for $18 \mathrm{~h}$ in PDB containing 30 or $150 \mu \mathrm{M}$ progesterone or 0.1\% DMF. Fungal samples were observed in an Olympus B51 microscope using interference phase microscopy, or in a Nikon SMZ800 stereomicroscope.

\subsection{Statistical analyses}

Due to the great variability observed in the organism, results were expressed as percentage of transformed progesterone. Values in percentage were obtained by comparing the peak areas corresponding to progesterone and its derivate derived from the HPLC analyses. Mean \pm standard error from mean (S.E.M.) was calculated from the indicated number of independent experiments. Data were analyzed using Graphpad Prism 3. One-way ANOVA and Student $t$-tests were applied as appropriate.

\section{Results}

\subsection{Progesterone is transformed by an inducible enzyme system in F. oxysporum}

To assess whether $F$. oxysporum is able to transform progesterone, the organism was pregrown in PDB for $16 \mathrm{~h}$ and $150 \mu \mathrm{M}$ of the steroid was added during $2 \mathrm{~h}$, a time sufficient to induce progesterone-transforming enzymes in other fungal systems [21,22]. Mycelia were chloroform-extracted and steroid content was analyzed by HPLC and mass spectrometry. Progesterone-induced mycelia showed a significant increase in progesterone-transforming activity compared to the uninduced control which received $0.1 \%$ DMF (Fig. $1 \mathrm{~A}$ ). To confirm that the increased transformation of progesterone was due to an inducible rather than a constitutive enzyme activity, the protein synthesis inhibitor cycloheximide was added simultaneously with the 


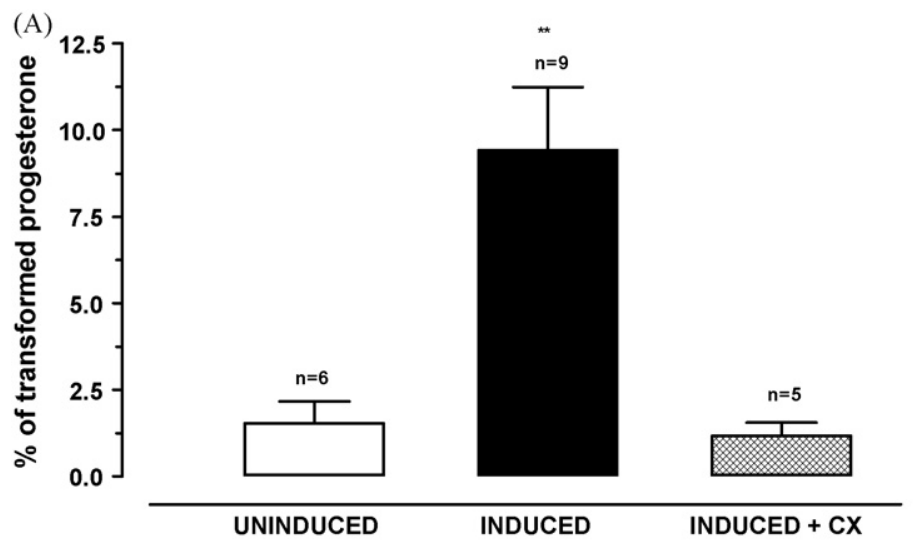

(B)<smiles>CC(=O)[C@H]1CC[C@H]2[C@@H]3CCC4=CC(=O)CC[C@]4(C)[C@H]3CC[C@]12C</smiles>

Progesterone<smiles>CC(=O)[C@H]1C[C@@H](O)[C@H]2[C@@H]3CCC4=CC(=O)CC[C@]4(C)[C@H]3CC[C@]12C</smiles>

15?-hydroxyprogesterone

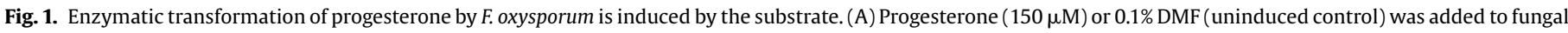

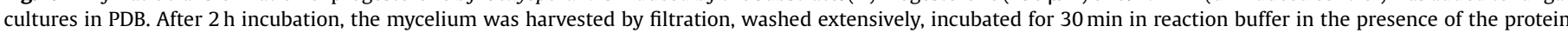

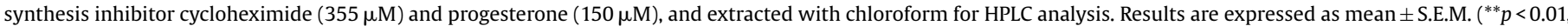

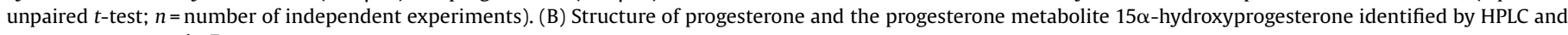
mass spectrometry in F. oxysporum.

inducer progesterone. In the latter case the presence of transformed progesterone was negligible, confirming de novo synthesis of progesterone-transforming enzyme (Fig. 1A).

The major hydroxylated product was identified by mass spectrometry as $15 \alpha$-hydroxyprogesterone (Fig. 1B). This result is consistent with the findings in other species and formae speciales of Fusarium [10-12,14]. However, extremely low amounts of $15 \beta$ hydroxyprogesterone were also detected.

\subsection{Progesterone metabolites accumulate predominantly in the extracellular medium}

Enzymatic transformation of $150 \mu \mathrm{M}$ progesterone into $15 \alpha-$ hydroxyprogesterone was followed over a time period of $240 \mathrm{~min}$. The hydroxylated product was first detected after $45 \mathrm{~min}$, both in mycelium and in the extracellular medium. The content of $15 \alpha-$ hydroxyprogesterone in the mycelium reached a maximum after $60 \mathrm{~min}$, decreasing after $180 \mathrm{~min}$ to finally fall to 0 after $360 \mathrm{~min}$ (Fig. 2). The hydroxylated product was predominantly extracellular, suggesting that $F$. oxysporum transforms progesterone into a more hydrophilic compound which is extruded into the surrounding medium.

The effect of progesterone concentration on the induction of transforming enzyme activity was studied by applying 15,30 , or $150 \mu \mathrm{M}$ progesterone in the induction assay. As shown in Table 1, $30 \mu \mathrm{M}$ was the minimal concentration of progesterone required to induce a response of a similar magnitude as the one observed with $150 \mu \mathrm{M}$.

A lower concentration of steroid $(30 \mu \mathrm{M})$ was therefore used. In this case, the level of $15 \alpha$-hydroxyprogesterone in the mycelium was maximum after $60 \mathrm{~min}$ (Fig. 3A), but decreased to 0 only after $180 \mathrm{~min}$, when all the product was present in the extracellular medium (Fig. 3B).

\subsection{The heterotrimeric G-protein $\beta$ subunit Fgb1 mediates progesterone response via cAMP}

The role of the MAPK Fmk1 and the G-protein $\beta$ subunit Fgb1 in mediating the induction of progesterone-hydroxylating enzyme was studied, using targeted gene knockout mutants. Hydroxylation of $30 \mu \mathrm{M}$ progesterone in the different strains was followed over a time span of $240 \mathrm{~min}$ (Fig. 3). As previously observed in the wild

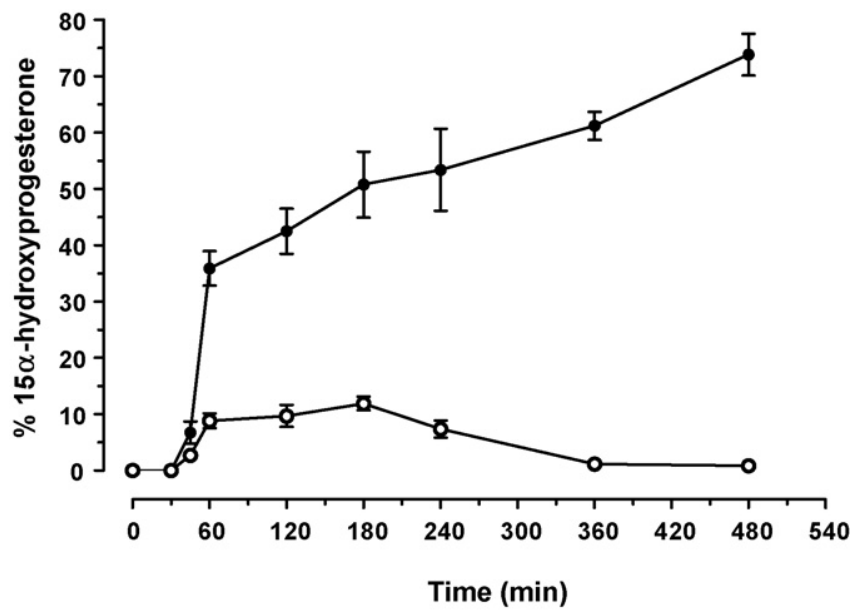

Fig. 2. $15 \alpha$-hydroxyprogesterone accumulates predominantly in the extracellular medium. Distribution of $15 \alpha$-hydroxyprogesterone in mycelium (empty circles) and medium (solid circles) of $F$. oxysporum induced for different time intervals by $150 \mu \mathrm{M}$ progesterone. After the indicated time periods, mycelium and medium were separated by filtration and steroids extracted with chloroform. The amount of $15 \alpha$-hydroxyprogesterone was determined by HPLC and the percentage of transformed progesterone calculated. Results are expressed as mean \pm S.E.M. from five independent experiments ( $p<0.001$, one-way ANOVA). 

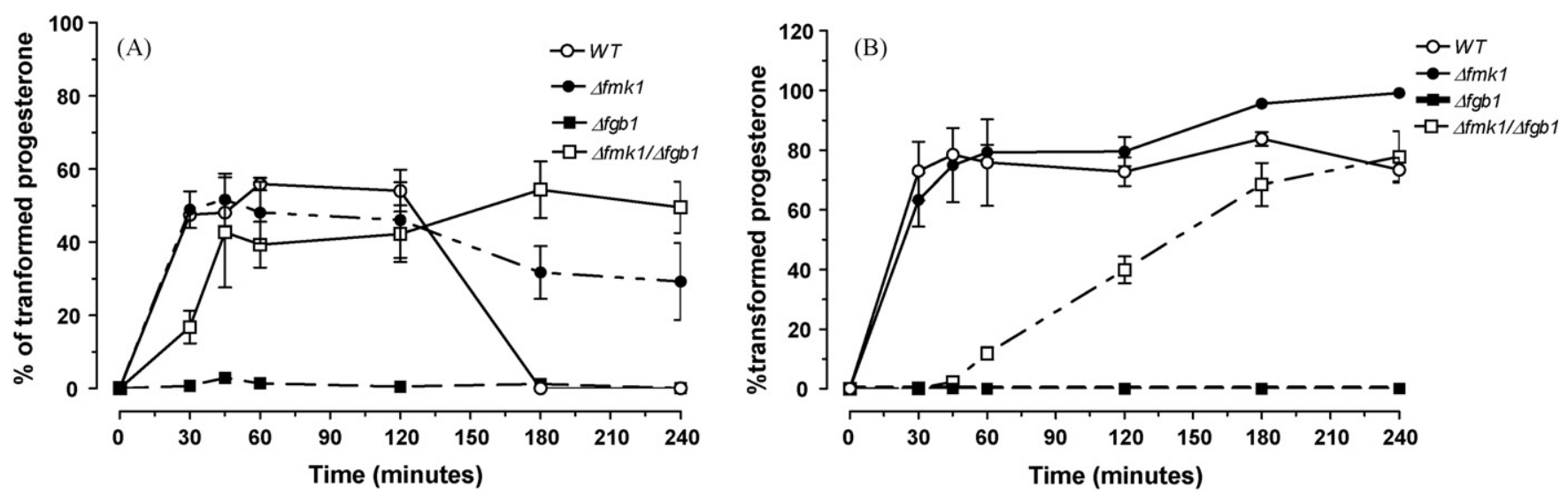

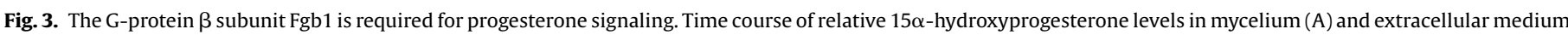

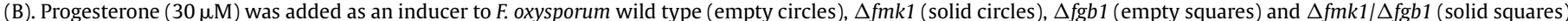

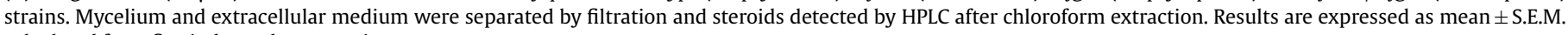
calculated from five independent experiments.

Table 1

Transformation of progesterone into $15 \alpha$-hydroxyprogesterone by F. oxysporum.

\begin{tabular}{lll}
\hline Progesterone $(\mu \mathrm{M})$ & \multicolumn{2}{l}{ \% Transformed progesterone } \\
\cline { 2 - 3 } & Mycelium (\%) & Medium (\%) \\
\hline 15 & $14.8 \pm 14.8, n=4$ & $12.68 \pm 1.51, n=5$ \\
30 & $12.38 \pm 8.73, n=6$ & $47.93 \pm 13.62, n=4$ \\
150 & $8.12 \pm 1.94, n=5$ & $52.42 \pm 3.66, n=3$ \\
\hline
\end{tabular}

Induction of $15 \alpha$-progesterone hydroxylase was performed for $2 \mathrm{~h}$ with the indicated concentrations of progesterone, mycelia were harvested and used for the progesterone transformation assay (see Section 2). Results are expressed as mean \pm S.E.M. calculated from the indicated independent experiments.

type, transformed progesterone in the mutants was mostly excreted into the extracellular medium (Fig. 3B). Progesterone transformation in the $\Delta f m k 1$ strain was at least as efficient as in the wild type. Indeed, transformation in the mycelium was still active after 180 and $240 \mathrm{~min}$ (Fig. 3A), and $15 \alpha$-hydroxyprogesterone accumulated to even higher levels in the extracellular medium (Fig. 3B). By contrast, $15 \alpha$-hydroxyprogesterone was almost undetectable both in the mycelium and the extracellular medium of the $\Delta f g b 1$ strain, suggesting that Fgb1 is required for induction of progesteronetransforming enzyme. Interestingly, the amount of transformed progesterone in the double mutant strain $\Delta f m k 1 \Delta f g b 1 \# 37$ reached levels approaching those of the wild type, although a significant delay was detected in extracellular hydroxyprogesterone accumulation (Fig. 3B). To test whether Fgb1 mediates induction of progesterone-hydroxylating enzyme through the cAMP pathway, induction experiments were performed in PDB supplemented with 10 mM cAMP. As shown in Fig. 4A and B, addition of exogenous CAMP restored the ability of the $\Delta f g b 1$ strain to hydroxylate progesterone to wild type levels. cAMP also increased the amount of progesterone transformation in the wild type. However, both in the wild type and the $\Delta f g b 1$ strain, enzyme activity was not detected when cAMP was added in the absence of the steroid as inducer (Fig. 4A). The latter result finds its explanation in the fact that the transduction signal leading to transformation of progesterone is not specific (see Section 4). Taken together, these results suggest that Fgb1 mediates induction of $15 \alpha$-progesterone hydroxylase by progesterone through the cAMP pathway.

\subsection{Progesterone inhibits hyphal growth rate in F. oxysporum}

In order to test the possible inhibitory effect of progesterone on hyphal growth of $F$. oxysporum, $10^{5}$ microconidia of the wild type strain were placed on PDA plates containing progesterone $30 \mu \mathrm{M}$ or $0.1 \% \mathrm{DMF}$ as a negative control. Progesterone reduced the rate of colony growth by approximately $30 \%$ compared to the control

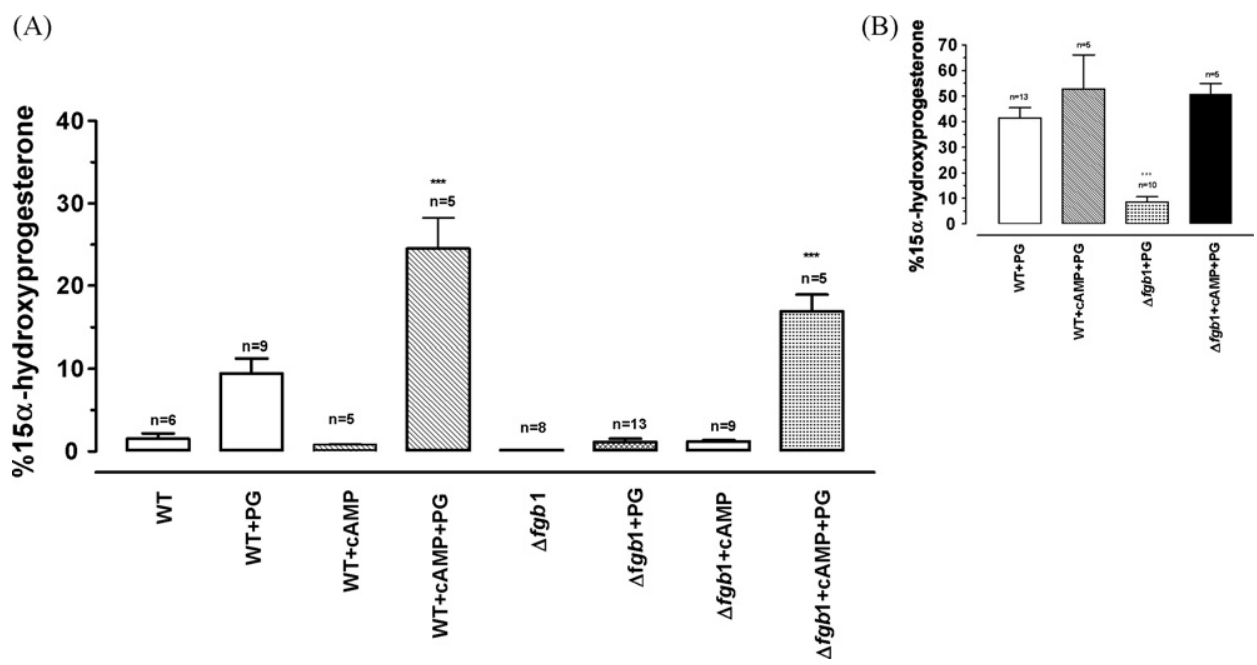

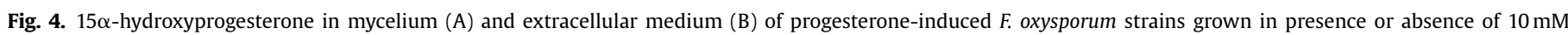
exogenous cAMP. Results are expressed as mean \pm S.E.M. ( $n=$ number of independent experiments; ${ }^{* * *} p<0.0001$, one-way ANOVA, Bonferroni post-test). 
(A)
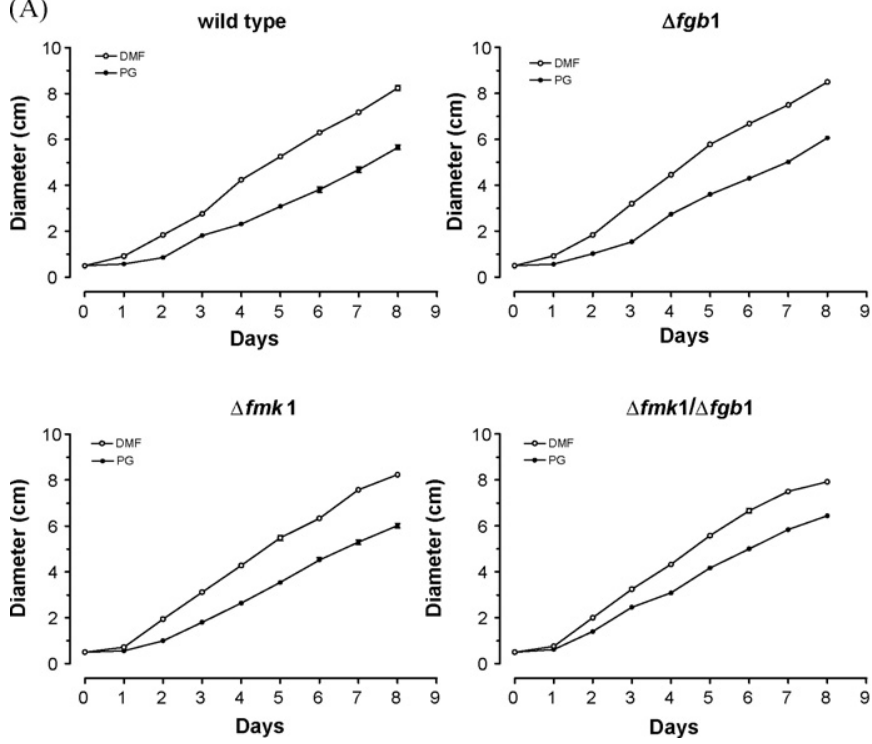

(B)

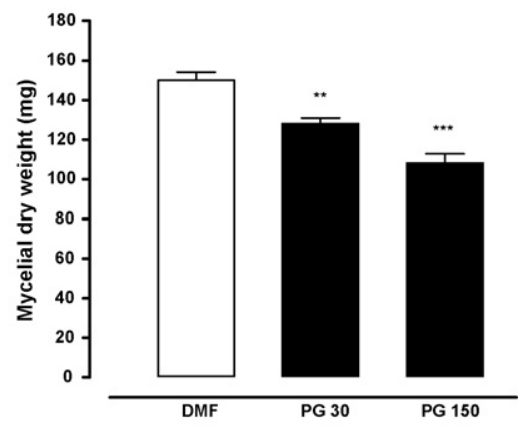

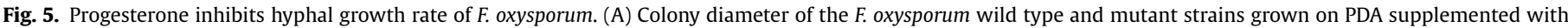

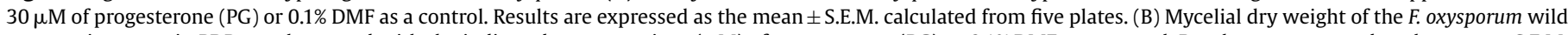

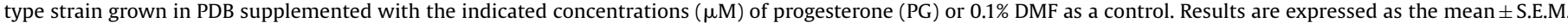
calculated from eight independent experiments $\left({ }^{* *} p<0.001\right.$; ${ }^{* * *} p<0.0001$, one-way ANOVA, Bonferroni post-test).

(Fig. 5A; $p<0.0001$, one-way ANOVA). To confirm that the reduction in colony diameter was indeed due to inhibition of hyphal growth, mycelial dry weight was determined in liquid cultures grown in the presence of 30 or $150 \mu \mathrm{M}$ progesteroneor $0.1 \% \mathrm{DMF}$ as a control (Fig. 5B). Both concentrations of progesterone caused a significant decrease in mycelial dry weight compared to the control $(p<0.01$, one-way ANOVA). Microscopical analysis of fungal colonies grown either on solid or liquid medium with $30 \mu \mathrm{M}$ progesterone or $0.1 \%$ DMF revealed no clear differences in hyphal morphology, suggesting that progesterone reduces mycelial growth of $F$. oxysporum without significantly affecting hyphal morphology.

\section{Discussion}

In the present study we explored the enzymatic system leading to progesterone hydroxylation in F. oxysporum f.sp. lycopersici. We found that progesterone is transformed into the more water-soluble metabolite $15 \alpha$-hydroxyprogesterone by a substrateinducible enzyme activity. We show that this induction is mediated by the G-protein $\beta$ subunit Fgb1, most likely through the cAMP pathway.

\subsection{Progesterone induces $15 \alpha$-progesterone hydroxylase in $F$. oxysporum}

Microbial steroid biotransformation, and specifically, progesterone hydroxylation is industrially important for the production of corticosteroids, thus prompting an interest in the ability of filamentous fungi to transform steroids. Here we show the presence of progesterone hydroxylating enzyme system in the tomato vascular wilt pathogen $F$. oxysporum f.sp. lycopersici. Hydroxylation occurred predominantly at position $15 \alpha$, consistent with the hydroxylation pattern reported in other species of Fusarium such as F. solani, F. moniliforme, F. lini or F. culmorum, and in the forma specialis F. oxysporum f.sp. cubense [10-12,14]. However, occasional hydroxylation at other sites has been reported [12,14], and in the present study trace amounts of $15 \beta$-hydroxyprogesterone were also detected.

F. oxysporum mycelia pre-exposed to progesterone for $2 \mathrm{~h}$ had dramatically increased progesterone-transforming enzyme activity compared to uninduced mycelia (Fig. 1). This result suggests that progesterone-hydroxylating activity is induced by presence of the substrate in the medium. Since progesterone can diffuse through biological membranes and presumably also through the fungal membrane $[23,24]$, it could be argued that the progesterone added during the $2 \mathrm{~h}$ induction period could act itself as a substrate during the subsequent enzymatic assay. Thus, the increase in enzyme activity detected in the induced mycelium would be explained simply by the presence of a higher amount of substrate rather than a real enzyme induction. However, two lines of evidence suggest that $15 \alpha$-progesterone hydroxylase activity in $F$. oxysporum is subject to real induction by progesterone. First, reducing the amount of inducing progesterone in the medium fivefold from $150 \mu \mathrm{M}$ to $30 \mu \mathrm{M}$ did not significantly reduce the degree of enzyme activity (compare Figs. 2 and 3). Second, when the protein synthesis inhibitor cycloheximide was added together with the inducer progesterone, no $15 \alpha$-progesterone hydroxylase activity was detected confirming the presence of a mechanism for progesterone-dependent induction of hydroxylating enzyme activity.

The biochemical nature of the progesterone-hydroxylating enzyme in $F$. oxysporum is currently unknown. In $R$. nigricans [7] and Cochliobolus lunatus [25], steroid hydroxylases were shown to depend on cytochrome P450 and NAPH-cytochrome $c$ reductase. This class of enzymes catalyzes a variety of reactions responsible for conversion of xenobiotics into less toxic compounds that are readily extruded [26]. In $F$. oxysporum, the self-sufficient cytochromes P450nor which functions in fungal denitrification and P450foxy, which hydroxylates fatty acids, have been described $[27,28]$. In the closely related species $F$. moniliforme, the inducible dehydroepiandrosterone (DHEA) $7 \alpha$-hydroxylase contains a cytochrome P450 [29]. Our finding that progesterone reduces mycelial growth of $F$. oxysporum may suggest the involvement of a cytochrome P450 enzyme in the ability of $F$. oxysporum to hydroxylate progesterone, although further biochemical studies are needed to confirm this hypothesis.

\subsection{The G-protein $\beta$ subunit Fgb1 plays a key role in progesterone signaling}

We studied the role of two conserved signaling pathways, the Fmk1 MAPK cascade and the cAMP pathway, in the induction of 
$15 \alpha$-progesterone hydroxylase. Both pathways were shown previously to regulate development and virulence in a large number of fungal species [30]. Whereas deletion of the fmk1 gene in F. oxysporum had no significant effect, a knockout mutant lacking the heterotrimeric G-protein $\beta$ subunit Fgb1 was almost completely impaired in induction of $15 \alpha$-progesterone hydroxylase (Fig. 3). Fgb1 was previously shown to control colony morphology, conidiation and virulence in $F$. oxysporum by regulating intracellular cAMP levels [19,31]. We found that addition of exogenous cAMP completely restored the ability of the $\Delta f g b 1$ mutant to induce progesterone hydroxylating activity, indicating that the progesterone signal is transmitted via the cAMP pathway (Fig. 4).

The exact mechanism whereby progesterone signaling is activated in F. oxysporum is currently unknown. In R. nigricans, evidence has been obtained for direct binding of progesterone to a G-proteincoupled membrane receptor [8]. If a similar mechanism is operating in $F$. oxysporum, the G $\beta$ subunit Fgb1 could be part of the receptor signaling complex. However, in such a linear model the ability of exogenous cAMP to induce $15 \alpha$-progesterone hydroxylase in the $\Delta f g b 1$ mutant should be independent of the presence of the steroid inducer. By contrast, we found that cAMP alone failed to induce progesterone-hydroxyl ting activity in the absence of progesterone, both in the wild type and the $\Delta f g b 1$ strain. This unexpected result can be explained with the fact that the signal leading to transformation of progesterone in $F$. oxysporum as well as in other filamentous fungi is not specific. Steroids are not present in the environment. Therefore, the presence of progesterone as inducer would be crucial to direct the machinery towards the final result.

The partially restored progesterone-transforming activity in $\Delta f m k 1 / \Delta f g b 1$ double mutant (Fig. 3 ) is unlikely to be an artifact, since it was obtained in two independent double mutants. The most straightforward interpretation is that Fgb1 acts as a positive regulator of progesterone signaling, whereas Fmk1 represses induction of $15 \alpha$-progesterone hydroxylase. Indeed, transformation of progesterone in the mycelium of the $\Delta f m k 1$ strain was still active at time points when that of the wild type approached zero. Moreover, this mutant accumulated significantly higher levels of $15 \alpha$-hydroxyprogesterone in the medium, suggesting that Fmk1 may be involved in feedback repression of progesterone hydroxylase activity. Whether the two pathways converge directly on a common downstream effector such as a transcription factor, and why relief from Fmk1-mediated repression is much more pronounced in the $\Delta f g b 1$ background remains to be determined.

\subsection{Biological role of progesterone hydroxylation}

Progesterone reduced mycelial growth rate of $F$. oxysporum both on solid and liquid media (Fig. 5). This result indicates that an important biological function of progesterone hydroxylation is the transformation of the fungitoxic compound progesterone into a less toxic product. Moreover, when studying the partition of $15 \alpha$-hydroxyprogesterone between mycelium and medium, we noted that most of the hydroxylated product was found in the extracellular medium. This finding points to a second biological function of progesterone transformation, namely its conversion into the more hydrophilic product $15 \alpha$-hydroxyprogesterone which is readily excreted by $F$. oxysporum. Extrusion of $15 \alpha-$ hydroxyprogesterone appears to take place concomitantly with steroid transformation (Figs. 2 and 3). The mechanism through which $15 \alpha$-hydroxyprogesterone is released into the medium is currently unknown. One possibility is that the metabolite is actively exported by ATP binding cassette $(A B C)$ transporters, a large family of proteins which actively export a variety of substrates across the plasma membrane [32]. ABC transporters cover several roles in fungi, including protection of phytopathogenic species against toxic plant defense products (phytoalexins) or allow secretion of viru- lence factors [33]. Interestingly, progesterone was recently shown to induce upregulation of two multidrug resistance (MDR) $A B C$ transporters genes in Candida albicans, CDR1 and CDR2 [34,35].

As shown in Fig. 3A, the pool of intracellular hydroxylated progesterone in the in the $\Delta f m k 1$ mutant declined much more slowly than in the wild type strain. It can be speculated that Fmk1 regulates activity of $A B C$ transporters in F. oxysporum either at the transcriptional or the post-translational level. This idea is supported by a number of studies in humans. Treatment of hepatocarcinoma cells with the specific ERK MAPK inhibitor U0126 resulted in decreased mRNA levels of two ABC transportes, MDR-1 and LPR [36]. Similarly, NIH3T3 cells showed a decreased activity of the MDR-1 promoter following treatment with the MEK inhibitor PD98059 [37]. Future research should provide more insights into the mechanism of transport of $15 \alpha$-hydroxyprogesterone from the mycelium into the surrounding medium.

\section{Acknowledgments}

The authors are grateful to Marjan Kužnik for technical assistance, to Spela Petric for suggestions and to Drs. Polona Zalar and Rok Romih for microscopic analysis. A.P. was supported by the Marie Curie Research Training Network MRTN-CT-2005-019277 (SIGNALPATH).

\section{References}

[1] S.B. Mahato, S. Garai, Advances in microbial steroid transformation, Steroids 62 (1997) 332-345.

[2] M.A. Avery, J.R. Woolfrey, Antiinflammatory steroids, in: M.E. Wolff (Ed.), Burger's Medicinal Chemistry and Drug Discovery, vol. 5, 1997, pp. 281-376.

[3] M. Zakelj-Mavric, I. Belic, Hydroxylation of steroids with $11 \alpha$ hydroxylase of Rhizopus nigricans, J. Steroid Biochem. 28 (1987) 197-201.

[4] M. Vitas, K. Smith, D. Rozman, R. Komel, Progesterone metabolism by the filamentous fungus Cochliobolus lunatus, J. Steroid Biochem. Mol. Biol. 49 (1994) 87-92.

[5] K. Breskvar, Z. Ferencak, T. Hudnik-Plevnik, The role of cytochrome P450 ${ }_{11 \alpha}$ in detoxification of steroids in the filamentous fungus Rhizopus nigricans, J. Steroid Biochem. Mol. Biol. 52 (1995) 271-275.

[6] N. Jeraj, H. Lenasi, K. Breskvar, The involvement of cAMP in the growth inhibition of filamentous fungus Rhizopus nigricans by steroids, FEMS 242 (2005) 147-154.

[7] K. Breskvar, T. Hudnik-Plevnik, Inducibility of cytochrome P450 and NAPHcytochrome $c$ reductase in progesterone treated filamentous fungus Rhizopus nigricans, J. Steroid Biochem. 14 (1981) 395-399.

[8] H. Lenasi, A. Bavec, M.Zorko, Membrane bound progesterone receptors coupled to G proteins in the fungus Rhizopus Nigricans, FEMS miocrobiol. Lett. 213 (2002) 97-101.

[9] H. Lenasi, K. Breskvar, Specific interactions of steroids, arylhydrocarbons and flavonoids with progesterone receptors from the cytosol of the fungus Rhizopus nigricans, J. Steroid Biochem. Mol. Biol. 91 (2004) 273-284.

[10] C. Casas-Campillo, M. Bautista, Microbiological aspects in the hydroxylation of estrogens by Fusarium moniliforme, Appl. Microbiol. 13 (1965) 977-984.

[11] A. Capek, O. Hanc, Microbiological transformation of steroids XII. Transformation of steroids by different species and strains of Fusaria, Folia Microbiol. 5 (1960) 251-256.

[12] T. Kolek, A. Swizdor, Biotransormations XLV. Transformations of 4-ene-3-oxo steroids in Fusarium culmorum culture, J. Steroid Biochem. Mol. Biol. 67 (1998) 63-69.

[13] T. Kolek, Biotransformation XLVII: transformations of 5-ene steroids in Fusarium culmorum culture, J. Steroid Biochem. Mol. Biol. 71 (1999) 83-90.

[14] M.R. Wilson, W.A. Gallimore, P.B. Reese, Steroid transformations with Fusarium oxysporum var. cubense and Colletotrichum musae, Steroids 64 (1999) 834-843.

[15] A. Swizdor, T. Kołek, Transformations of 4- and 17alpha-substituted testosterone analogues by Fusarium culmorum, Steroids 70 (2005) 817-824.

[16] A. Di Pietro, M.P. Madrid, Z. Caracuel, J. Delgado-Jarana, M.I.G. Roncero, Fusarium oxysporum: exploring the molecular arsenal of a vascular wilt fungus, Mol. Plant Pathol. 4 (2003) 315-326.

[17] G.M. Armstrong, J.K. Armstrong, Formae speciales and races of Fusarium oxysporum causing wilt disease, in: P.E. Nelson, T.A. Toussoun, R.J. Cook (Eds.), Fusarium: Disease, Biology and Taxonomy, State University Press, University Park, PA, USA, 1981, pp. 391-399.

[18] A. Di Pietro, F.I. Garcia-Maceira, E. Meglecz, M.I.G. Roncero, A MAP kinase of the vascular wilt fungus Fusarium oxysporum is essential for root penetration and pathogenesis, Mol. Microbiol. 39 (2001) 1140-1152.

[19] J. Delgado-Jarana, A.L. Martinez-Rocha, R. Roldan-Rodriguez, M.I.G. Roncero, A. Di Pietro, Fusarium oxysporum G-protein $\beta$ subunit Fgb1 regulates hyphal growth, development, and virulence through multiple signalling pathways, Fungal Genet. Biol. 42 (2005) 61-72. 
[20] A. Di Pietro, M.I.G. Roncero, Cloning expression and role in pathogenicity of pg1 encoding the major extracellular endopolygalacturonase of the vascular wilt pathogen Fusarium oxysporum, Mol. Plant Microbe Interact. 11 (1998) 91-98.

[21] T. Hudnik-Plevnik, B. Cresnar, Factors affecting the induction of $11 \alpha-$ hydroxylase of progesterone in the filamentous fungus Rhizopus nigricans, J. Steroid Biochem. 35 (1990) 749-751.

[22] M. Vitas, K. Smith, J. Plavec, J. Kesselmeier, T. Pajic, D. Zigon, A. Ferlan, S. Kelly, R. Komel, Induction of steroidal hydroxylase activity by plant defence compounds in the filamentous fungus Cochliobolus lunatus, Chemosphere 38 (1999) 853-863.

[23] R. Plourde, H. Hafez-Zedan, Distribution of steroid 1-dehydrogenation and side chain degradation enzymes in the spores of Fusarium solani: causes of metabolic lag and carbohydrate independence, Appl. Microbiol. 25 (1973) 650-658.

[24] I. Oren, S.J. Fleishman, A. Kessel, N. Ben-Tal., Free diffusion of steroid hormones across biomembranes: a simplex search with implicit solvent model calculation, Biophys. J. 87 (2004) 768-779.

[25] C. Horold, K. Undisz, H. Groh, R. Sahm, W. Shade, R. Komel, Bioconversion of steroids by Cochliobolus lunatus, J. Basic Microbiol. 26 (1986) 335-339.

[26] D. Werck-Reichhart, R. Feyereisen, Cytochromes P450: a success story, Genome Biol. 1 (2000) 1-9.

[27] N. Nakayama, A. Takemae, H. Shoun, Cytochrome P450foxy, a catalytically selfsufficient fatty acid hydroxylase of the fungus Fusarium oxysporum, J. Biochem. 119 (1996) 435-440.

[28] T. Kitazume, N. Takaya, N. Nakayama, H. Shoun, Fusarium oxysporum fatty acid subterminal hydroxylase (CYP505) is a membrane bound eukaryotic counterpart of Bacillus megaterium cytochrome P450BM3, J. Biol. Chem. 275 (2000) 39734-39740.
[29] A.C. Cotillon, J. Doostzadeh, R. Morfin, The inducible and cytochrome P450 containing dehydroepiandrosterone $7 \alpha$-hydroxylating enzyme system of Fusarium moniliforme, J. Steroid Biochem. Mol. Biol. 62 (1997) 467-475.

[30] K.B. Lengeler, R.C. Davidson, C. D'Souza, T. Harashima, W.C. Shen, P. Wang, X. Pan, M. Waugh, J. Heitman, Signal transduction cascades regulating fungal development and virulence, Microbiol. Mol. Biol. Rev. 64 (2000) 746-785.

[31] S. Jain, K. Akiyama, T. Kan, T. Ohguchi, R. Takata, The G protein $\beta$ subunit FGB1 regulates development and pathogenicity in Fusarium oxysporum, Curr. Genet. 43 (2003) 79-86.

[32] S. Raychaudhuri, A.A. Prinz, Uptake and trafficking of exogenous sterols in Saccharomyces cerevisiae, Biochem. Soc. Trans. 34 (2006) 359-362.

[33] M. Urban, T. Bhargava, J.E. Hamer, An ATP-driven efflux pump is a novel pathogenicity factor in rice blast disease, EMBO J. 18 (1999) 512-521.

[34] D. Banerjee, N. Martin, S. Nandi, S. Shukla, A. Dominguez, G. Mukhopadhyay, R. Prasad, A genome-wide steroid response study of the major fungal pathogen Candida albicans, Micopathologia 164 (2007) 1-17.

[35] D. Banerjee, G. lelandais, S. Shukla, G. Mukhopadhyay, C. Jacq, F. Devaux, R Prasad, Responses of pathogenic and nonpathogenic yeast species to steroids reveal the functioning and evolution of multidrug resistance transcriptional networks, Eukaryot. Cell 7 (2008) 68-77.

[36] J. Guan, X.P. Chen, H. Zhu, S.F. Luo, B. Cao, L. Ding, Involvement of extracellular signal-regulated kinase/mitogen-activated protein kinase pathway in multidrug resistance induced by HBx in hepatoma cell line, World J. Gastroenterol. 10 (2004) 3522-3527.

[37] Q. Yang, S. Poole, K.A. Borkovich, A G-protein beta subunit required for sexual and vegetative development and maintenance of normal $\mathrm{G}$ alpha protein levels in Neurospora crassa, Eukaryot. Cell 1 (2002) 378-390. 